\title{
Freedom and Desire: A Quest for Spiritual Journey in James Joyce's Novel Ulysses/A Portrait of the Artist as a Young Man
}

* Muhammad Bilal, PhD Scholar \& Lecturer in English (Corresponding Author)

** Naseem Ullah Khan, Lecturer in English

*** Syed Qasim Shah, Lecturer in English

\begin{abstract}
This study, Freedom, and Desire: A quest for a spiritual journey in the novel by James Joyce, describes the journey of the main character of the story from his adolescence to the best way of conceptualizing the dynamic, multilateral relationship between individual experience and sociocultural scope, since it recognizes the causal significance of culture but also recognizes individual choice and changes. The researcher examines the true desire which enables him to embrace his creative spirits "the actual experiences" which also symbolize freedom. This claim is formed by contemplating how many historical shifts in the socio-cultural context, i.e. the increase in freedom of choice, the shift in interpersonal patterns, the loss of traditional values, the loss of religious understanding, and the increasing conflict between the desire for individuality and the complexity of achieving it, have led to changes in the essence of true intentions and modern personhood. For this research, a qualitative method is adopted in the framework of Locke on Freedom (2015). It also points out and aims at the need to establish a new perspective on the provision of spiritual treatment in the field of freedom and desire, which focuses on improving the particular spiritual journey of the person, rather than simply reassuring spiritual distress. A man should not have to restrict himself to limited ideas, for this one has to go beyond limitation to change his mind which is the ultimate reality of advancement in life.
\end{abstract}

Keywords: Art, Freedom, Identity, Life, Modernity, Spirituality Freedom, Spirituality, Art, Life, Self-Identity, Modernity

\section{Introduction}

People may have a desire for democracy as well as a desire for freedom constraints. This is because equality and limits of freedom are both important to live peacefully. The entire freedom cannot be accomplished because, when you take away the restrictions, you take away the freedoms. Baer, Kaufman, and Baumeister, (2008) assert that our social psychology depends largely on the ability to reason in terms of freedom of expression, and the popular assumption that we are inclined to say on our desires and therefore to choose our intended course of action is fundamental to our everyday social awareness. Without the laws governing society, people are free to do what they want each other to do without a certain penalty. If you look at the benefits and drawbacks of both arguments, it becomes simpler. Nichols and Knobe, (2007); Pizarro and Helzer, (2010); Vohs and Schooler, (2008) These authors, though the same acknowledging that actions may be hierarchical or constrained by the physical, mental, and social environments, likewise inform our comprehension of agency, causal attribution, and moral obligation. There are several types of desires depicted in the major works, including the desires for wealth, strength, holiness, status, and, of course, flesh. Although many people may have felt these desires, such intimate desires are rarely articulated in public. Chernyak, (2009); Kushnir, Wellman, and Nichols, (2004) Chernyak, Kushnir, and Wellman, (2010) express opinion in their research on developmental psychology have shown that children have some clear understanding of freedom and choice. Young children, for example, know that their actions, as well as those of other individuals, can do so. In other terms, children say that all else is fair, including their acts and those of others, "might have been different." The literary beacons of the period have

\footnotetext{
* Bacha Khan University, Charsadda, Pakistan Email: muhammadbilal29@gmail.com

** Bacha Khan University, Charsadda, Pakistan Email: naseemduke77@gmail.com

*** Bacha Khan University, Charsadda, Pakistan Email: qasimshahpmd@ gmail.com
} 
presented these desires both discreetly and openly, but they are mild in contrast with the overt expression of desire found in modern times.

Freedom is so desirable since many of the constraints of freedom do not give us the ability to govern our bodies. Controlling our bodies is the one thing we have control over. A significant number of forbidden freedoms are crimes; you are a victim, for example, of the use of drugs, adultery, suicide, vagrancy, minor belongings, and age restrictions on the purchasing of pornographic materials. Any of these offenses are punishable by statute. What sets these apart from most crimes is that you chose to victimize yourself, except perhaps in the case of prostitution, if they are compelled to sell themselves against their own will.

The right to freedom of expression can be described as war and sometimes a psychological war as Stephen and his progress in life as an infant to a mature boy. It's a fight that continued until the end of Stephen's life. It's a battle between freedom of speech and social intolerance. There are many battles in this war that an individual is forced through design by what comes in their way.

The question of how to judge Stephen Dedalus' development towards artistic maturity is essential to the interpretation of A Portrait of the Artist as a Young Man. Face with tremendous external and internal pressures surrounding religious values, family disruptions, and sexual desires, Dedalus wants to become an artist and to be alive. In this regard, Commentators are largely disappointed as to whether the specifics of the story reflect his present and potential success or failure. In this difference, the autobiographical aspect plays an important role in the decades following the Second World War, when Joyce and modernism change from being contemporary to being part of the canon of past literature. This research is profoundly rooted in a qualitative nature that ultimately analyses the contextual structure. The purpose of the paper is rooted in the desire for freedom that leads to the right to freedom of speech, which can be described as war and, at some point, a psychological war, as Stephen and his progress in life as a child to a mature boy. It is between the independence of experience and social intolerance with the real experience of life that makes him capable of moving through the thick environment of his conservative family history that Stephen rejects the old conventional social ideals, the questionable essence of faith, and his family to make his own.

\section{Background to the Study}

Joyce's life and the connection of his life to his work are of great interest to critics and readers. Much of the story is closely linked to Joyce's experience in Ireland, including the Jesuit schools Stephen attended, first Clongowes Wood College, a pre-eminent boarding school, and then Dublin, Bel vedere College, and University College. Stephen's eventual departure from Dublin at the end of the story parallels Joyce's departure from the Continent in 1902 and eventually in 1904. The positions and dates have been printed after Stephen's diary, "Dublin 1904/Trieste 1914", concern, on the one hand, the decade-long period during which Joyce has written A Portrait. On the other hand, they can also be read as predicting the next stage of Stephen's life, which would include exile and writing, maybe even writing a novel based on his youth. This latter inference is possible in part because Joyce does not make the dates of the operation clear. He must have known that many readers would have felt that "Dublin, 1904" offered a fair year for Stephen's diary and his departure for unnamed places, which might include Trieste. By not providing explanations, or even basic facts, such as Stephen's age (referred to in only one passage when he confesses at 16), the narrator turns to us the task of formulating explanations and filling in missing data. "Trieste, 1914" poses concerns that cannot be addressed within the story. Nor there any strong signs of Stephen's possible success or failure in the future. Some critics, most notably Wayne Booth (1983), complain that Joyce is not offering consistent signals to judge Stephen. Identifying Stephen with Joyce makes a positive judgment possible, but it does so from outside the story. Since this identification is speculative, the narrative remains open to competing interpretations.

It is clear that man still lives in the company of his fellow beings. The word "society" is interpreted in a different sense; "society" refers to the complicated network of social relations that each person has in common with his fellow men, so that culture is abstract, not actual, in nature. We can't reach it, but we can fill it because the culture is in the mind of the person. Portrait of the Artist is all about Stephen Dedalus, who is just a child in Ireland at the end of the 19th century. Gradually, to live a life dedicated to writing, he discards all his social, intimate, and religious constraints. As a boy, Stephen's Catholic faith and Irish citizenship have a great influence on his actions and beliefs; as a 
young man, he expresses his intention to marry a young girl next door, Eileen, a Protestant. His parents are so angry with him that he is hiding under the table, and his governess, Dante, tells him that if he does not apologize, "the eagles will come and pull out his eyes." Stephen Dedalus, a boy in Ireland at the end of the nineteenth century, gradually nullifies all his social and religious constraints on living a life devoted to the search for freedom and the pursuit of spiritual gain in literature. Stephen's society, the Catholic faith, and Irish nationality have had a heavy impact on his views and tried to figure out his way.

\section{Review of Spirituality}

The words "religiosity" and "spirituality" are often used interchangeably, but while religion refers to the religious philosophy that the individual adheres to, spirituality denotes a person's experience or relationship with God (Burkhardt, 1989). Reed (1992) describes spirituality as one's "capacity for self-transcendence" that enables one to experience "interpersonally" "interpersonally" and "Trans personally." Consequently, Hungelmann, Kenkel-Rossi, Klassen, and Stollenwerk (1985) define spiritual well-being as a sense of "cohesive interrelationship between self, nature, and the Ultimate Other" Lane (1987) also emphasizes enlightenment and interrelationship as important elements of the human condition, give hope but being free. According to Reed (1992), the key aspects of personal religious faith usually involve optimism, generativity, deep sense, spiritual expertise, and religious behavior. Lane (1987) considers the results of one's spirituality as an internal change, surrender, commitment, and hardship, while Haase, et al. (1992) believe that an individual explores the nature of human values and the transcendence of self through spirituality. Clark, (1991); Peterson, (1985); Stoll, (1989) defines "religious needs or the need for identification, significance, affection, trust, repentance and innovation" (Berggren-Thomas, 1995). Although scholars interpret spirituality and its representations in radically different ways, the universal concepts of consciousness, others, and a spiritual being; the desire to transcend one's self, space, and time; and generativity or imagination can be seen in the literature.

The interpretation of the research studies conducted by Brennan and Missine (1980) on the participation of the aged in organized religious practices is contradictory, with some results suggesting that the participation increases with age and others revealing a decrease. While these results are varied, faith is still seen as a way for elderly people to comply with life transitions (McCulloch, 1997). Pieper (1981) defines the advantages that the old themselves gain from church membership as social contact, moral support, adding purpose to life, and promoting spiritual growth. Abraams (1980) has identified that religious practice has also been established to enhance the social interaction of a group of institutionalized elderly men (Berggren-Thomas, 1995). In a related study of breast cancer participants, Mickley, Soeken, and Belcher (1992) originate that their feelings of hope, as calculated by the Nowotny Hope Scale, have improved as the women's internal religious scores amplify. In a study of the countryside old community, Tellis-Nayak (1982) notes that, as religiosity develops, so does their sense of purpose in life. More recent findings have shown that seriously ill adults, in contrast to individual ill older people, have a greater sense of faith and a corresponding increase in positive affect (Reed, 1987).

\section{Research Methodology and Theoretical Framework}

The present research is qualitative and the essence of the research is exploratory. For the study of the primary text, textual analysis is used as a primary text research tool, while secondary data has been obtained from other sources using a textual or close reading method. John Locke on Freedom (2015) has chosen as the theoretical context for current research. The theory provides a basis for the nature and freedom of will, which have played a significant role in the ideology of conduct and moral psychology. Locke gives identifiable descriptions of behavior and benevolence, of will and voluntary cooperation as compared to forced action and deferment and of liberty as compares to need.

\section{Research Objective}

The cause of the quest is to research comprehensively (depending on the cultural, social, and religious aspects) the development of ways and aims, the desire for freedom in the world, and the spiritual and psychological journey of the phenomenon of human life in the world. The aims for the achievement of the research objectives of the article are: to know the meaning of the desire for freedom of thought and its perception utilizing a spiritual and creative journey.

Research Question 
What is the significance of the desire for freedom and pursuit of the spiritual journey in James Joyce's novel?

\section{Analysis and Discussion}

We follow Stephen across his childhood with his first year at Conglowes, succeeding in his little victory at Father Conmee's workplace. The beginning condenses the direction that Stephen follows in the novel as he moves towards his intention to become an artist; we are also exposed to the key forces that make up Stephen: Irish nationalism, Catholicism, and his exceptional sensitivity. The trip, which relies on Stephen's creative spirits and the actual experiences of life, brings about historic shifts in the socio-cultural sense of true identity and contemporary self-interest. Stephen is acutely aware of his youth and lack of comprehension in the presence of his father and Uncle Charles. He cannot join their conversations, understand their language, and understand the "true world" in which they talk; waiting for the time of his own adult life. It perceives that Stephen has a sense of a certain great part that he's planning to promote in the world .... Do we think that this affinity to elaborateness is just part of his personality? Since it is clear that they are:

"His elders often spoke about subjects close to their hearts, about Irish politics... Words which he does not understand, he says to himself over and over until he has learned them by heart: and through them, he has an insight into the truth of their culture. He, too, seems to get closer and secretly began to plan for the large part of his life that he feels awaiting him, the essence of which he apprehends only dimly." (James Joyce, p. 110)

Stephen is a great observer and a deep thinker from a very early age, and the upheavals of time direct his intent, and for the first time, home is an insecure thought for him. Since the family relocated to Blackrock recently, and Stephen can feel that there are many more transitions on the move, he says, "he realized vaguely that his father is in trouble and that is why he wasn't returning to Clongowes himself. For some time now he has felt his house being subtly altered, and these changes to his unmovable views of the universe are too many little shocks."(p.113)

The household would become alarmingly destabilized. Stephen is constantly aware of the world around him that a shift in the family climate is related to the shortcomings of his father. The move to Dublin of the family is also exceptional. Conscious and mindful of the situation that "the sudden flight from Blackrock's comfort and reverie, the gloomy foggy city passage, the thought of a bare cheerful home in which they are to live makes his heart heavy now, and once again an intuition, an expectation of the future... servants have whispered often in the hall with each other...and why his father has been standing on the hearth with his back to the flames, talking... (p. 114) here, youth impotence is the wrath of Stephen, but he can't do anything about it, of course. Nothing is thrilling about childhood here; in this new setting (Dublin), Stephen lost a carefree spirit at times in Blackrock when he visited his mother's family and, “...His bitterness is caused by many, far and close.... angry with himself for having been young and the beheading of impatient dumb drives, angry too with the shift from riches to squalor and insincerity around him in the country. His wrath, however, lent the vision nothing. He patiently chronicles what he sees, detaches himself, and secretly tastes his mortifying taste....." (p. 115)

Stephen seems so isolated from his family that it seems as if they are not related - the isolating impression also has something to do with the fact that all of his emotions and experiences are internalized and have never communicated with anyone at this point as "...he sees his hopeless loneliness too plainly... The restless disgrace and rancor that separated him from his mother and brother and sister have tried to come near or bridge his lives. He felt that he was with them he was hardly a single blood, but he was in the magical partnership of breeding, fostering and fostering a boy..." (p. 149)

Here, Stephen begins to distinguish his faith from belief. Stephen is concerned with the intention of the high priest will feel no pleasure at the unexpected blast of music - and he knows that his artistic intelligence of attractiveness is lively again. His first encounter leads him on a different, self-chosen course, as, "...the music passes in an instant, as the first bars of sudden music always do, over the fantastic fabrics of his mind, dissolving them painlessly and noiselessly as a sudden wave dissolves the sand-built turrets of children.... raise his eyes to the priest's face and, seeing in it a mirthless reflection of the sunken day, detached his hand slowly which has acquiesced faintly in the companionship..." (p. 214) 
The childhood of Stephen is starting to fall apart. Though he felt that in his sinful time he had left everything behind, in his family and his faith, there are still signs of his childlike self. Now, however, he is also breaking away from the standards of his mother and "...a dim antagonism gather force within him and darken his mind like a cloud against her disloyalty and when it passed, cloudlike.... he is made aware dimly and without regret of a first noiseless sundering of their lives..." (p. 218). We have the Christ-like image of the new Stephen, finally certain about his destiny, rising from the burial site to a mature Stephen. He chose what to do with his own cultural and social experiences, is it a question that will be addressed in the study? Can Stephen become a savior of his own? "...his soul has arisen from the grave of boyhood; spurning her grave-clothes... he would create proudly out of the freedom and power of his soul, as the great artificer whose name he bore, a living thing, new and soaring and beautiful, impalpable, imperishable..." (p. 224)

Stephen begins to rebel in his new system of spiritual self-discipline. The transition from the Catholic faith to the appreciation of the physical as part of beauty is important. The keys to Ireland's entrapment and escape are core themes. Stephen is forced to fear for his soul after he has allowed himself fleshly pleasure. Feverishly, he comes back to the chapel. He seeks to suppress his impulses as a person: sensational sensitivity, an interest in beauty. But there is the sensual world of true life: ironically, the priest suggests that he should look at the priesthood which restores him to his destiny. With his rough and tensile stress of physicality, he is interested in the world of life and people. He realizes he will "sin again" and understands that he is not made to live a life without blemish. Instead, he will live the whole life and realize that he will make huge mistakes in his growth. Too clean, too sterile is the sanctuary of the Holy Virgin. He likes a mess and consequently lives his life. Yet the body in the world doesn't have his anxieties. The sight of the other boys reminds him that his own half-cultivated body is shameful. It reminds us that his development is incomplete both physically and spiritually. Although the sensual and the physical are attracted, disgrace often appears to remain there at unpredictable times and “...He's alone. He's alone. He is joyful and close to life's wild heart. He's alone, young, willing and wild-hearted ..." (p. 225)

Mrs. Dedalus has the mistaken idea that Stephen's university life has changed. While she has somehow been right, we know that what separated him from his home and family is Stephen's sense of purpose and his new identity. He has now so many voices that offend and threaten to humiliate his childhood pride, a whistle from her father about the murmurs of her mother and the cries of an unknown psychopath. Once more, we see the love of his childhood rediscovered by Stephen while he is always an adult as a child, now he is proud of his young and rebellious character, as Dedalus says "....ah, it's a scandalous shame for you, Stephen, says his mother, and you'll live to rue the day you set your foot in that place. I know how it has changed you..." (p. 228)

The difference from childhood to adolescence is accompanied by a range of movements and deaths: one can see the move to Dublin and the transition to Belvedere and the death of Uncle Charles who is depicted at the beginning of the chapter as an inextricable part of the childhood of Stephen. Stephen discovers on his journey to Cork that he has changed so fully that his childhood is a faint memory. Somehow, Stephen's destiny is close to death; he does not die but completely vanished. His mind is often an inconvenience. His father's nostalgia and encouragement are too insightful for him. He has the wisdom of his dad, but he has become painfully conscious of the many mistakes of his dad. The intensity of his sexual longing sometimes breaks him apart. His sensibilities are far enough from romance or affection in the church to know. He is very open to himself. He chose to live a life of a prostitute, following his desires which he placed behind his culture, land, and even Christianity. His choice is a major turning point in his life. He's announcing that, "...this race produces me and this land and this life, he says. I'm going to say who I am. ..." (p. 258)

Life is not always straightforward; it also has challenges, and the challenges are to face them courageously, to let life's beauty act as comfort which enhances sorrow, by making happiness, sorrow, triumph, loss, the night and the day the two sides of the coin. Likewise, life is packed with moments of joy, happiness, success, and comfort, marked by sorrow, loss, deceit, and trouble. We see Stephen's classmates increasingly more accept him. Whilst he is a stranger, some events here predict that he will become a reluctant leader in the future. At first, because of its fragile attitude, small scale, and social embarrassment, it is a simple bullying target, but Stephen demonstrates some characteristics that are seeds of a tremendous personality. Despite his sensitivity, he is no whiner: he remembers the advice of his father that when he is dragged into the Wells cesspool, he would never 
touch anyone. And he's hard enough to come to the rector to complain about the injustice of Father Dolan. However, these intense moments are not easy for Stephen. His athletic incompetence makes him nervous and fearful. He is an extremely sensitive child. He's virtually quiet in all his interactions with the other boys. If he does not agree with their decisions, he keeps his opinions to himself. But in the emerging categories, Stephen never lost his power and wanted to abandon his land and bring newness to the ideas of language and religion. Whatever he practiced, he never satisfied that was the reason why Stephen recognized the twentieth century and wanted to move away from the slavery of social and religious ideals to make a new one, because, “... when the soul of man is born...there are nets flung at it to hold it back from flight. You talk to me of nationality, language, religion. I shall try to fly by those nets..." (p. 258)

We see Stephen's classmates increasingly more accept him. Whilst he is a stranger, some events here predict that he will become a reluctant leader in the future. At first, because of its fragile attitude, small scale, and social embarrassment, it is a simple bullying target, but he demonstrates some characteristics that are seeds of a tremendous personality. Despite his sensitivity, he is no whiner: he remembers the advice of his father that when he is dragged into the Wells cesspool, he would never touch anyone. And he's hard enough to come to the rector to complain about the injustice of Father Dolan. However, these intense moments are not easy for Stephen. His athletic incompetence triggers his anxiety and terror; he is an extremely sensitive child. He's virtually quiet in all his interactions with the other boys. If he does not agree with their decisions, he keeps his opinions to himself. It highlights the reactions of Stephen on the occasion. For example, at a Christmas dinner, Stephen is a silent witness to the debate between his father and Dante, since he has little understanding, and not a strong believer in spiritualism, to free his soul and fly like a free bird. As life experiences are from childhood to adulthood, they will benefit from my community where I live, i.e. my culture, my land, and my spiritual journey. Stephen has a clearer understanding of the Roman Catholic Church and is revolting against the three main institutions of the state of the Church and the family. He withdraws to the suburbs of society. He retains a sense of equilibrium in a claustrophobic society and seeks to step away from the art of experience, to find a new form of freedom. In this A Portrait, there is a stream of consciousness in which events are recalled in chronological order, but free association brought them to mind as silence at the beginning and eventually exile from all, even from religion and culture. And strive to create a new creation at the end of the day, and that's a new spiritual way of - its own — and that's what it means and,

“...I will tell you what I will do and what I will not do. I will not serve that in which I no longer believe.... my home, my fatherland, or my church: and I will try to express myself in some mode of life or art as freely as I can and as wholly as I can, using for my defense the only arms I allow myself to use ... silence, exile, and cunning..." (p. 268)

The interpretation of the object of beauty by the artist is a suspended spiritual state, "the delight of the heart." Stephen believes that it is at the heart of the aesthetic philosophy of Stephen and his present personal spirituality. The claim that the transformation of Stephen was unavoidable implies that perhaps the person he is now is the one he was destined to be all over. But Stephen's theory places the artist on an equal footing with the idea of God. We are not aware that the artist is not truly God. The artist transcends work and remains distant, divine, and unprepared by the idealized act of creative growth. Indeed, he might sit down and cut his nails.

"The artist feels this supreme quality when his imagination is the first to conceive of an aesthetic image. The mind in Shelley's enigmatic moment resembles fading coal beautifully. The moment in which the high beauty, the pure radiance of the aesthetic image, -----is the silent light stasis of aesthetic enjoyment, a very heartily state which, using a press that is almost as beautiful as Shelley's, is called the enchantment, the enchantment, the spiritual state Luigi Galvani...." (p. 269)

The argument that the transformation of Stephen is inevitable means that maybe the person he is today who he was meant to be as "I mean, tell Stephen, I'm not like I am now, like I have to be...." (p. 297). Adolescence is an unbelievably important period of conflict for Stephen. We conclude that he is a "leader fearing for his own authority" as a performer and essayist, very popular among his peers. (P.103). But Stephen's isolation from others is reinforced by the plot. He is filled with feelings and ideas that he can't express to others. In a way that the world still cannot express, it hits him. He 
sounds often hollow to the voices of his elders and peers, but he still has no rebellion. The way he wants to react is not rebellion. He is not isolated from his family or peers; rather, he is isolated from them. It is a world of newness to create yourself and to make possible your way only if you resist the fear of the heart and the fear of losing because it prevents your development. With the knowledge of the mistakes, he wants to give up all pharmacology of the planet to make sure the soul's eternity. For this reason, he acknowledges the fear of the heart.

"You've made me acknowledge the doubts I have. Tell you what I'm not afraid of, either. I'm not afraid to be alone or to be spurned by someone else or to leave everything I have to leave. And I'm not afraid to make a mistake, a major mistake, a life-long mistake, and maybe as long as eternity, too...." (p. 305)

It depends on the person's attitude to the institution of the family, to the organized religion, and the country, but the rebellion against the existing norms of proper conduct must be seen from Stephen's point of view. And it is more important, to be frank with oneself than to go along with social norms and conventions. He finds honesty in his self to be the most important factor in life, regardless of the price to be paid for this then Stephen's life rebellion is a very brave act of significance to the 20th century. The Roman Catholic Church is the prevailing force in the world, and to go against it means that it will be ostracized and left out of society and will never come back. Stephen needs to immerse himself in the world of perception and to explore the essence of humankind. Stephen revolted against his family, the church, and his country, at the very opening of the Christmas dinner, where there was a confrontation between his father and Dante. He's struggling a lot, but he faces it like a brave boy and a rebellion against life itself. He does not try to avoid the bad experiences of life, but wants to reject the very essence of his race and culture and purifies his soul in the very furnace of his experiences, so he accepts his life and says, "Welcome to it, O life! For the millionth time, I will encounter the truth of experience and forge the uncreated conscience of my race in the smithy of my mind. ..." (pp. 310-311)

\section{Conclusion}

Stephen is, as we see, a very religious child, fearing hell and enthralled by Mary's Virgin. But his connection to religion was soon troubled; his growth is followed by vital intellectual content. He has shown a sophisticated aesthetic theory for college students who are deeply indebted to Aristotle and Aquina. Stephen's way of thinking and his methods often reflect the Jesuits' influence and education. He has been passionate about his latest conceptions about beauty. This reflects his evolution; it turned his sensitivities into a methodical and obsessive approach to aesthetics and distracted his appreciation of beauty. It should be remembered that he is concerned with the threatened Irish identity. He does not try to engage in politics, but his goal is to construct his race's conscience. As an artist, he supported Ireland, and only if he is alone will he be an artist. Fleeing the old identity of commodities, politics, and faith in search of a new way of spirituality is deeply interwoven and flight also symbolizes the notion of escape. He is dreamy to watch the birds fly over him as they once did. The name Stephen refers to the flight of Dedalus, and when he leaves Ireland, he calls it on Dedalus. He became a courageous, self-confident young man, ready to confront his convictions just as Stephen began to rebel in his new system of spiritual self-discipline. The transition from catholic piety to physical acceptance as part of beauty is a crucial phenomenon. He is forced to fear for his soul after he has allowed himself fleshly pleasure. Feverishly, he comes back to the chapel. He seeks to suppress his impulses as a person: sensational sensitivity, an interest in beauty. But there is the sensual world of true life: ironically, the priest suggests that he should look at the priesthood which restores him to his destiny. But his anxieties about the world of the body are not without his. The sight of the other boys reminds him of how embarrassing his own half-grown body. This instant reminds us of Stephen's physical and spiritual growth. Although the sensual and physical are drawn, shame still appears to hang on in uncertain times. He escapes from this acceptance. He comes to view the advice of the priest as a trap, a way for the Jesuits to take him out of his destiny and to make him fulfill his goals. Escape becomes a mighty motive. Stephen, Dedalus, is used as a legendary name, a symbol of Stephen's birth. He leaves Ireland to change his mind and move beyond his own country which restricts his freedom. 


\section{References}

Baer, J., Kaufman, J. C., \& Baumeister, R. F. (Eds.) (2008). Are we free? Psychology and free will. New York: Oxford University Press.

Burkhardt M (1989) Spirituality: analysis of the concept. Holistic Nursing Practice 3, 69-77.

Berggren-Thomas, P., \& Griggs, M. J. (1995). Spirituality in aging: Spiritual need or spiritual journey? Journal of Gerontological Nursing, 21(3), 5-9.

Chernyak, N., Kushnir, T., \& Wellman, H. M. (2010). Developing notions of free will: Preschoolers' understanding of how intangible constraints bind their freedom of choice. Proceedings of the Thirty-Second Annual Meeting of the Cognitive Science Society, 2602-2606.

Hungelmann J, Kennel-Rossi E, Klassen L \& Stollenwerk RM (1985) Spiritual well-being in older adults: harmonious interconnectedness. Journal of Religion and Health 24, 147-153.

Haase, J. E., Britt, T., Coward, D. D., Leidy, N. K., \& Penn, P. E. (1992). Simultaneous concept analysis of spiritual perspective, hope, acceptance, and self-transcendence. Image: The Journal of Nursing Scholarship, 24(2), 141-147.

Kushnir, T., Wellman, H. M., \& Chernyak, N. (2009). Preschoolers' understanding of freedom of choice. Proceedings of the Thirty-First Annual Meeting of the Cognitive Science Society, 8792.

Lane, J. A. (1987). The care of the human spirit. Journal of Professional Nursing, 3, 332-337.

McCulloch, C. A. (1997). How spirituality transforms the care of older persons (pp. 135-148). Paulist Press.Nichols, S., \& Knobe, J. (2007). Moral responsibility and determinism: The cognitive science of folk intuitions. Nous, 41, 663- 685.

Nichols, S. (2004). The folk psychology of free will: Fits and starts. Mind and Language, 19, 473502.

Pizarro, D. A., \& Helzer, E. (2010). Freedom of the will and stubborn moralism. In R. F. Baumeister, A. R. Mele, \& K. D. Vohs (Eds.), Free will and consciousness: How might they work?. New York: Oxford University Press.

Reed PG (1992) an emerging paradigm for the investigation of spirituality in nursing. Research in Nursing and Health 15, 349-357

Reed, P. G. (1987). Spirituality and well-being in terminally ill hospitalized adults. Research in nursing \& health, 10(5), 335-344.

Rickless, S. (2015). Locke on freedom.

Stoll RI (1989) the essence of spirituality. In Spiritual Dimensions of Nursing Practice (Carson VB Ed.). W. B. Saunders, Philadelphia, pp. 14-23.

Vohs, K. D., \& Schooler, J. W. (2008). The value of believing in free will: Encouraging a belief in determinism increases cheating. Psychological Science, 19, 49- 54. 